\title{
Alterações da forma e tamanho da mandíbula em pacientes com terceiros molares
}

\section{impactados}

\author{
Alteration in mandible form and size in patients with impacted third molar \\ Alteración en la forma y tamaño de la mandíbula en pacientes con tercer molar impactado
}

Recebido: 31/03/2021 | Revisado: 10/04/2021 | Aceito: 13/04/2021 | Publicado: 26/04/2021

Jennifer Santos Pereira

ORCID: https://orcid.org/0000-0002-8763-3681

Universidade Estadual do Sudoeste da Bahia, Brasil E-mail: jenniferspodonto@gmail.com

Yvina Santos Silva

ORCID: https://orcid.org/0000-0003-4493-4406 Universidade Estadual do Sudoeste da Bahia, Brasil

E-mail: yvina95@gmail.com

Wagner Couto Assis

ORCID: https://orcid.org/0000-0001-7802-2443 Universidade Estadual do Sudoeste da Bahia, Brasil E-mail: wagnerassis2010@hotmail.com

Cezar Augusto Casotti

ORCID: https://orcid.org/0000-0001-6636-8009 Universidade Estadual do Sudoeste da Bahia, Brasil E-mail: cacasotti@uesb.edu.br

Lorena Andrade Nunes

ORCID: https://orcid.org/0000-0002-7453-7666 Universidade Estadual do Sudoeste da Bahia, Brasil E-mail: lorenunes2@gmail.com

\begin{abstract}
Resumo
Os terceiros molares quando desalinhados, podem provocar complicações para o paciente, e na prática oral especialmente no campo cirúrgico e ortodôntico. Esse estudo objetiva analisar alterações na forma e tamanho da estrutura óssea da mandíbula associadas a impactação de terceiros molares a partir da morfometria geométrica. Tratase de um estudo transversal, realizado com 110 radiografias panorâmicas de pacientes com idade de 18 a 25 anos, atendidos no Módulo de Odontologia da Universidade Estadual do Sudoeste da Bahia. Após obtenção das imagens de radiografias panorâmicas foram realizadas as medições, em seguida a análise generalizada de Procrustes, Função discriminante, validação cruzada e a distância de Mahalanobis. Não houve diferença significativa no tamanho da mandíbula entre os sexos dos grupos com e sem terceiros molares impactado ( $p>0.05$ ). Para o formato da mandíbula, identificou-se diferenças significativas $(\mathrm{p}<0.05)$ entre os grupos. Radiografias panorâmicas de indivíduos com dentes impactados foram classificados corretamente em $67,1 \%$ das vezes, enquanto no grupo controle 52,4\%. A distância de Mahalanobis apresentou diferenças significativas $(\mathrm{p}<0,05)$ entre radiografias de indivíduos com e sem terceiros molares impactados. Com base no outline, as radiografias de pacientes com dentes impactados apresentam expansão na região mentual e compressão na região do côndilo da mandíbula. Conclui-se que há alterações no formato da mandíbula, especialmente na região mentual e do côndilo, e isto, pode estar associado a impactação de terceiros molares.
\end{abstract}

Palavras-chave: Dente não erupcionado; Terceiro molar; Mandíbula.

\begin{abstract}
The third molars when misaligned, can cause complications for the patient, and in practice, especially in oral surgery and orthodontic field.This study aims to analyze changes in the shape and size of the jaw bone structure associated with the impact of third molars from geometric morphometry.This is a cross-sectional study, carried out with 110 panoramic radiographs of patients aged 18 to 25 years, attended at the Dentistry Module of the State University of Southwest Bahia. After obtaining panoramic radiographic images, measurements were made, followed by the generalized analysis of Procrustes, Discriminant function, cross-validation and Mahalanobis distance. There was no significant difference in the size of the mandible between the genders of the groups with and without impacted third molars ( $p>0.05)$. For the shape of the mandible, significant differences $(p<0.05)$ were identified between the groups. Panoramic radiographs of individuals with impacted teeth were correctly classified $67.1 \%$ of the time, while in the control group 52.4\%. The Mahalanobis distance showed significant differences $(p<0.05)$ between radiographs of individuals with and without impacted third molars. Based on the outline, the radiographs of patients with impacted teeth show expansion in the mental region and compression in the condyle of the mandible.It was concluded that there
\end{abstract}


are changes in the shape of the mandible, especially in the mental region and the condyle, and this may be associated with the impact of third molars.

Keywords: Unerupted tooth; Third molar; Manbible.

\begin{abstract}
Resumen
Los terceros molares, cuando están desalineados, pueden causar complicaciones al paciente, y en la práctica oral, especialmente en el campo quirúrgico y ortodóncico. Este estudio tiene como objetivo analizar los cambios en la forma y tamaño de la estructura del hueso mandíbular asociados al impacto de los terceros molares mediante la técnica de morfometría geométrica. Se trata de un estudio transversal, realizado con 110 radiografías panorámicas de pacientes de 18 a 25 años, atendidos en el Módulo de Odontología de la Universidad Estatal del Suroeste de Bahía. Luego de la obtención de imágenes radiográficas panorámicas, se realizaron mediciones, seguidas del análisis generalizado de Procrustes, Función discriminante, validación cruzada y distancia de Mahalanobis. No hubo diferencia significativa en el tamaño de la mandíbula entre los sexos de los grupos con y sin terceros molares impactados ( $p>0,05)$. Para la forma de la mandíbula, se identificaron diferencias significativas $(p<0.05)$ entre los grupos. Las radiografías panorámicas de individuos con dientes retenidos se clasificaron correctamente el $67,1 \%$ de las veces, mientras que en el grupo de control el 52,4\%. La distancia de Mahalanobis mostró diferencias significativas ( $\mathrm{p}<0.05)$ entre las radiografías de individuos con y sin terceros molares impactados. Según el Outline, las radiografías de pacientes con dientes impactados muestran expansión en la región mentoniana y compresión en la región del cóndilo de la mandíbula. Se concluye que existen cambios en la forma de la mandíbula, especialmente en la región mentoniana y el cóndilo, y esto puede estar asociado al impacto de terceros molares.
\end{abstract}

Palabras clave: Diente no erupicionado; Tercer molar; Mandíbula.

\title{
1. Introdução
}

A impactação de dentes permanentes ocorre quando um dente falha em irromper funcionalmente na arcada dentária no tempo esperado. Esta é uma condição clínica que necessita de um bom planejamento do tratamento (Ara \& Ayesha, 2016). A impactação dentária pode gerar diversas complicações como distúrbios nas articulações temporomandibulares, dor orofacial, neuralgias, reabsorção ou danos aos dentes adjacentes a eles (Lopes et al., 2020).

Um dente impactado representa um grande problema na prática oral, especialmente no campo cirúrgico e ortodôntico (Ali, 2015). A depender da posição e localização do dente impactado, no planejamento do atendimento, se faz necessário a utilização de recursos como a osteotomia e a odontossecção. Estes procedimentos podem aumentar o risco de complicações pós-operatórias, como alveolites, trismo e parestesias, além de fratura mandibular (Lopes et al., 2020).

A etiologia da impactação de dentes permanentes não está totalmente elucidada, e pode estar associada a fatores locais e sistêmicos (Lu \& Fan, 2019). Relacionados aos fatores locais estão a falta de espaço disponível, barreiras físicas, dentição em erupção distal, vertical direção do crescimento condilar, aumento do tamanho da coroa de dentes impactados, maturação tardia ou retardada, dentes supranumerários, tumores odontogênicos, trajeto de erupção anormal e fenda labiopalatina. Por outro lado, os fatores sistêmicos destacam-se a displasia cleidocraniana, síndrome de Down, deficiências endócrinas (hipotireoidismo e hipopituitarismo), doenças febris (Adeyemo et al., 2021; Lu \& Fan, 2019). Dentre os grupos dentários, os terceiros molares são frequentemente os mais impactados (Ara \& Ayesha, 2016).

O exame complementar mais utilizado para definir o diagnóstico e conduta clínica frente a casos de dentes impactados é a radiografia panorâmica em função da sua objetividade, precisão, padronização e reprodutibilidade (Gamba et al., 2016). Esse exame tem sido utilizado no estudo morfométrico de estruturas craniofaciais, por desempenhar um papel significativo no diagnóstico de diversas patologias, o que desperta interesse de diferentes áreas que trabalham com as estruturas da face, motivado pelas novas tecnologias que facilitam o diagnóstico e preparação do plano de tratamento (de Menezes \& Sforza, 2010; Nunes et al., 2018).

Os estudos morformétricos, podem ser realizados por meio da morfometria tradicional, que é um conjunto de métodos que utiliza medidas lineares como comprimentos, larguras, ângulos ou razões calculadas a partir de estruturas dos organismos, ou ainda a morfometria geométrica, que é uma análise estatística da forma e tamanho, capaz de preservar toda a informação geométrica contida nos dados originais, pois essa técnica utiliza coordenadas cartesianas denominadas de marcos anatômicos, e 
por isso é considerada uma análise mais robusta (Fornel \& Cordeiro-Estrela, 2012).

Essa metodologia pode ser aplicada em diversas área da saúde, seja para identificar: fatores de risco cardiovascular e metabólico em idosos (Pinto et al., 2020), pacientes com traço e anemia falciforme, em função de características relativas da forma da região craniofacial (Ferreira et al., 2020). Identificar variações na forma facial relacionadas à presença de diabetes, hipertensão e presença ou ausência de ambas as doenças (Nunes et al., 2018).

Pela importância acerca do conhecimento de características morfológicas da mandíbula e para um entendimento mais completo da etiologia da impactação de terceiros molares inferiores, o objetivo deste estudo foi analisar as alterações na forma e tamanho da estrutura óssea da mandíbula associadas a impactação de terceiros molares a partir da morfometria geométrica.

\section{Metodologia}

Trata-se de um estudo transversal, quantitativo que utiliza uma metodologia de analise morfométrica geométrica relatado em diversos trabalhos, tais como os de Bookstein (1986), Adams et al., (2004), Klingenberg E Monteiro (2005), Slice (2007), Klingenberg (2013). Trabalho obteve aprovado pelo Comitê de Ética em Pesquisa da Universidade Estadual do Sudoeste da Bahia (UESB), sob parecer favorável 3.845.829, CAAE: 28805020.7.0000.0055.

Inicialmente foi obtida a autorização do coordenador do Módulo de Odontologia da UESB para ter acesso ao banco de radiografias digitais dos usuários tomadas anteriormente com diferentes propósitos diagnósticos. Todas radiografias foram realizadas em um aparelho de raio x panorâmico digital EAGLE, Marca Dabi Atlante, de 85Kvp e $10 \mathrm{~mA}$. Em seguida, o responsável técnico pelo serviço de radiologia disponibilizou cópia digital de 2.621 radiografias panorâmicas realizadas no período de 2017 a 2020. Não houve necessidade de realizar exame clínico e manuseio dos prontuários, visto que as informações referentes aos usuários foram sexo e idade.

Do banco de imagens foram selecionadas radiografias panorâmicas de usuários de ambos os sexos, com idade de 18 a 25 anos, com presença dos terceiros molares superiores e inferiores. Foram excluídas radiografias que apresentavam: perda dentária, dentes em evolução intraóssea (exceto os terceiros molares); patologia ou condição de desenvolvimento que afetava a visibilidade da área de estudo (tumores, cistos, fraturas ou malformações); radiografias com evidências de cirurgia ortognática, trauma de face, uso aparelho ortodôntico ou contenção ortodôntica; Restaurações extensas; Anomalias dentárias; Agenesia dental e com qualidade de imagem inadequada (distorção ou alteração discrepante do contraste).

As radiografias foram classificadas em dois grupos de acordo com a presença ou não (grupo controle) de terceiros molares inferiores impactados, seguindo a classificação proposta por Winter e Pell E Gregory: normal (classe I, posição A) e impactado (Classe 2, posição B e Classe 3, posição C) (Lisboa et al., 2012).

A partir das imagens selecionadas foi criado um único arquivo com extensão TPS, por meio do programa tpsUtil (FJ Rohlf, 2019). Posteriormente no programa tpsDig2 (FJ Rohlf, 2017b) foram inseridos nas imagens radiográficas os marcos e semimarcos anatômicos (F. Rohlf, 2015). Em cada imagem da mandíbula foram inseridos trinta e oito pontos sendo 4 marcos e 34 semimarcos anatômicos, como pode ser visto na Figura 1. Os marcos foram selecionados para permitir uma boa representação da morfologia mandibular, para incluir apenas pontos de referência que são identificáveis em adultos e que já havia sido utilizado em outros estudos, na Tabela 1 apresenta a descrição dos pontos marcados na Figura 1. (Buck \& Vidarsdottir, 2004; Toro-Ibacache et al., 2019). 
Figura 1. Radiografia panorâmica com marcos (quadrado) e semimarcos (pontos em preto) anatômicos na mandíbula.

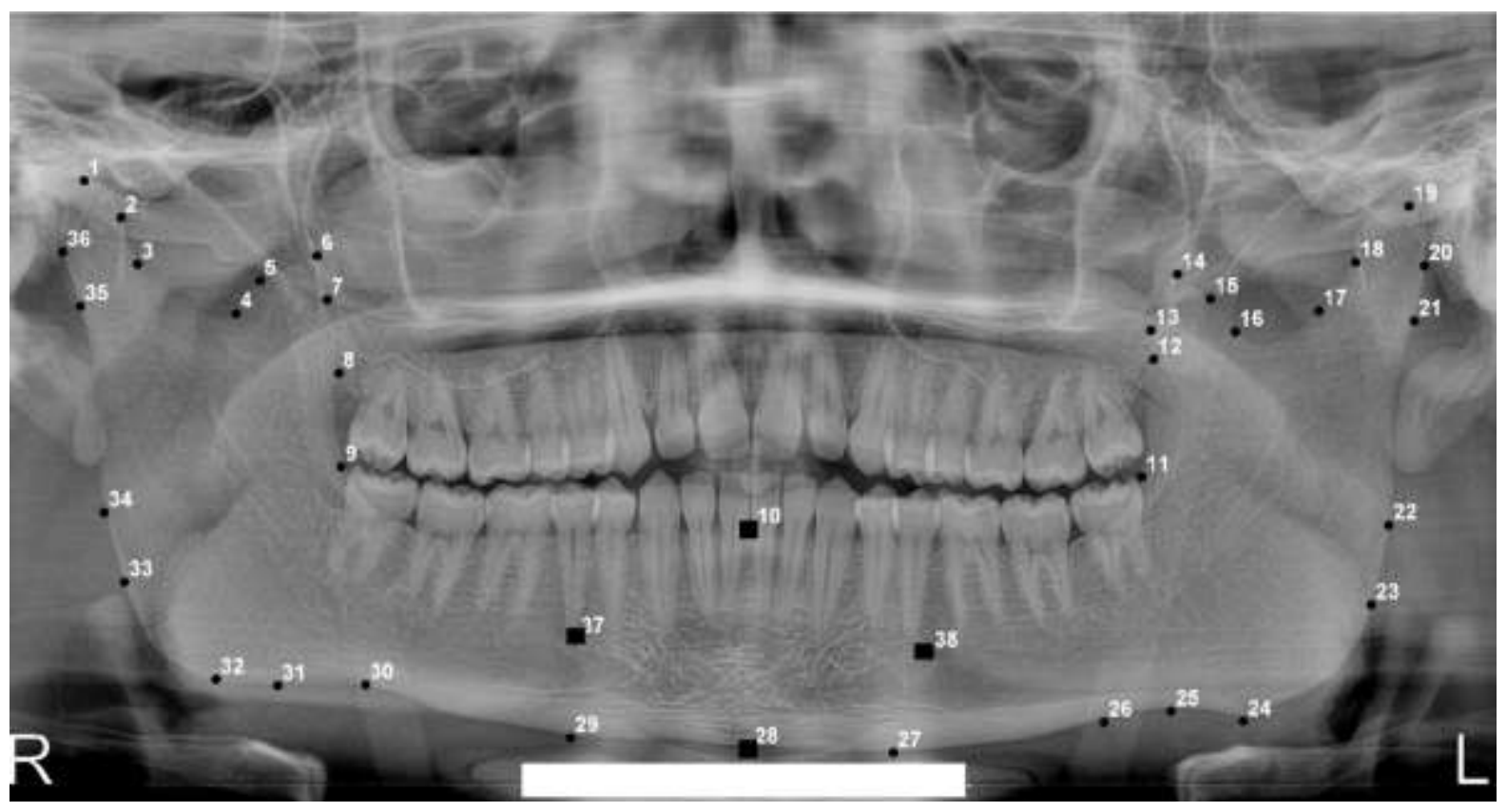

Fonte: Autores (2021).

Tabela 1. Descrição dos pontos anatômicos homólogos marcados nas radiografias panorâmicas.

\begin{tabular}{|c|c|c|}
\hline Ponto anatômico & Definição & Classificação \\
\hline $1-19$ & Ponto mais superior no côndilo mandibular & Semimarco anatômico \\
\hline $2-18$ & Ponto localizado na porção interna mais superior da cabeça do côndilo & Semimarco anatômico \\
\hline $3-17$ & Ponto localizado na porção interna mediana da cabeça do côndilo & Semimarco anatômico \\
\hline $4-16$ & Ponto mais inferior da porção interna do processo coronóide & Semimarco anatômico \\
\hline $5-15$ & Ponto médio da porção interna do processo coronóide & Semimarco anatômico \\
\hline $6-14$ & Ponto mais superior do processo coronóide & Semimarco anatômico \\
\hline $7-13$ & Ponto médio da porção externa do processo coronóide & Semimarco anatômico \\
\hline $8-12$ & Ponto mais inferior da porção externa processo coronóide & Semimarco anatômico \\
\hline $9-11$ & $\begin{array}{l}\text { Ponto mais posterior situado na superfície alveolar atrás do dente erupcionado } \\
\text { mais posterior (ou cripta para dente) }\end{array}$ & Semimarco anatômico \\
\hline 10 & Ponto infradental: o ponto mais alto do processo alveolar no plano médio & Marco anatômico \\
\hline $20-36$ & Ponto mais superior da articulação da cabeça do côndilo & Semimarco anatômico \\
\hline $21-35$ & Ponto mais inferior da articulação da cabeça do côndilo & Semimarco anatômico \\
\hline $22-34$ & Ponto localizado na borda posterior do ramo ascendente, mais para superior & Semimarco anatômico \\
\hline $23-33$ & Ponto localizado na borda posterior do ramo ascendente, mais para inferior & Semimarco anatômico \\
\hline $24-32$ & Ponto na borda inferior do corpo da mandíbula & Semimarco anatômico \\
\hline $25-31$ & Ponto na borda inferior do corpo da mandíbula & Semimarco anatômico \\
\hline $26-30$ & Ponto na borda inferior do corpo da mandíbula & Semimarco anatômico \\
\hline $27-29$ & Ponto localizado na borda do corpo da mandíbula na direção dos forames mentais & Semimarco anatômico \\
\hline 28 & Ponto gnatio: o ponto mais inferior da protuberância mental & Marco anatômico \\
\hline $37-38$ & Forame mentual direito e esquerdo: porção central do forame & Semimarco anatômico \\
\hline
\end{tabular}

Fonte: Autores (2021). 
A morfometria geométrica é uma análise estatística da forma, que não é baseada em medidas lineares ou ângulos, mas sim em coordenadas cartesianas chamadas marcos anatômicos (landmarks). As coordenadas cartesianas são distâncias espaciais, que podem ser definidas num plano e ter duas ou três dimensões (Slice, 2007).

Os semimarcos anatômicos são menos confiáveis, por isso são classificados como marcos do tipo III, desta forma, é necessário realizar o seu alinhamento, para isso foi utilizado o programa tpsRewl (Rohlf, 2017a). O alinhamento objetiva otimizar a posição dos semimarcos em relação à forma média. Os semimarcos de cada amostra são deslizados em relação a um modelo, em seguida, calcula-se a sobreposição de Procrustes dessas coordenadas, tornando-os marcos confiáveis (Mitteroecker \& Gunz, 2009).

As coordenadas desses marcos são submetidas a uma etapa de pré-processamento (Análise Generalizada de Procrustes) para padronizar a localização e orientação, eliminando os efeitos de rotação e translação, produzindo formas finais quase simétricas (Fornel \& Cordeiro-Estrela, 2012; Palmer, 1994). Posteriormente, todos os semimarcos deslizam em relação ao formato médio de Procrustes, concluindo o alinhamento (Mitteroecker \& Gunz, 2009).

As mensurações foram realizadas pelo mesmo pesquisador em triplicata, com intervalo de 3 dias entre as medições de uma mesma amostra. Esta técnica é utilizada para reduzir ou evitar erros associadas à medição. Quando pretende-se distinguir diferenças na variação entre os lados de duas ou mais amostras, visto que as diferenças entre os lados são frequentemente muito pequenas (geralmente $<5 \%$ e frequentemente $<1 \%$ do tamanho da característica), deve-se tomar muito cuidado durante a medição e a análise para maximizar a probabilidade de detectar diferenças entre as amostras (Palmer, 1994).

Para verificar a calibração do pesquisador foi empregado a Anova de Procrustes no programa MorphoJ (Klingenberg, 2019). Assim, foi aferido se a variação é em função do objeto estudado (entre as mandíbulas) ou do medidor. Após esse processo de calibração do pesquisador, foi realizado a marcação dos pontos anatômicos e analises morfométricas para toda a amostra.

A partir dos dados obtidos, que são as coordenadas cartesianas, foi realizada a análise de regressão para testar o efeito de Alometria em função do desenvolvimento, ou seja, a variação da forma em função do tamanho. Para a análise de tamanho a partir do Tamanho do Centróide foi realizada a Análise de Variância (ANOVA), que verifica se há diferenças generalizadas no tamanho dos indivíduos. O tamanho do centróide é caracterizado como a raiz quadrada do somatório dos quadrados das distâncias entre cada ponto de referência e o centroide (Bookstein, 1992).

A variação na forma das estruturas foi realizada análise de função discriminante, que gera valores de reclassificação verificando o quão bem os indivíduos da amostra são reclassificados de acordo com os grupos estabelecidos. A seguir realizouse a validação cruzada para determinar em que medida os indivíduos foram corretamente classificados dentro de cada grupo, com 1000 permutações. Foi realizada a projeção do outline para mapear as variações do formato das estruturas e facilitar a visualização dessa variação de forma gráfica. As análises foram realizadas no programa MorphoJ (Klingenberg, 2019).

\section{Resultados}

Foram coletadas 2.621 imagens radiograficas panorâmicas realizadas no período de 2017 a 2020, após aplicação dos critérios de inclusão e exclusão, foram selecionadas e incluídas 110 imagens de radiografias panorâmicas. As imagens foram subdividas em dois grupos: Grupo 1: radiografias panorâmicas de Terceiros molares inferiores irrompidos $(n=45)$, e que estavam no nível oclusal com o segundo e primeiro molar. Grupo 2 (Controle): Terceiros molares inferiores impactados $(\mathrm{n}=$ 65), com erupção incompleta ou abaixo do nível oclusal do segundo e primeiro molar.

Para a análise de regressão não foi encontrado valores significativos $(p>0,05)$ referente a presença de alometria. A One-Way ANOVA para análise do tamanho, a partir do tamanho centroide, não foram encontradas diferenças significativas para mandíbulas entre os grupos impactado e controle ( $p>0.05)$. 
A função discriminante utilizando a distância de Mahalanobis obteve valores significativos $(\mathrm{p}<0,05)$ entre as imagens radiográficas dos grupos impactados e controle. Na validação cruzada, imagens radiográficas panorâmicas de indivíduos com dentes impactados foram $67,1 \%$ classificadas corretamente, enquanto no grupo controle foi de $52,4 \%$.

A partir do outline foi possível identificar mudanças na forma entre os grupos analisados (Figura 2). No grupo com dentes impactados ocorreu encurtamento nas regiões mentual (pontos anatômicos 10,37,38,28,29,27) e do côndilo da mandíbula (pontos anatômicos 1, 19) (Figura 2). Já no grupo de indivíduos sem dentes impactados há uma expansão na região mentual e no côndilo da mandíbula (Figura 2).

Figura 2. Outline da mandíbula representando as duas morfologias do conjunto de dados. A linha cinza representa a forma média e a linha preta a variação do formato da mandíbula entre os pacientes que apresentam dentes impactados e normais.

\section{Normal}

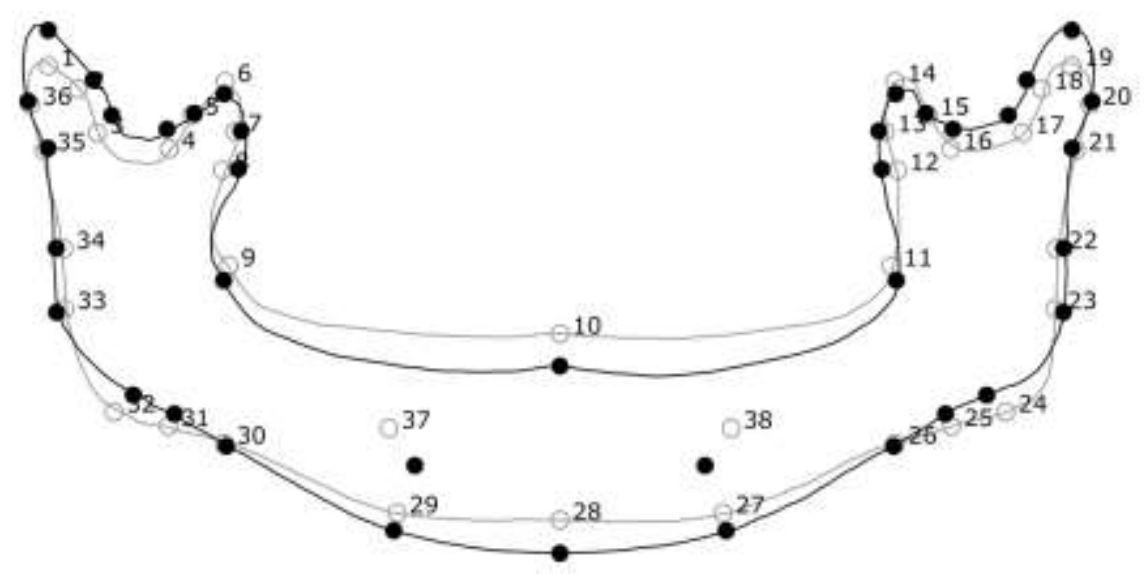

\section{Impactado}

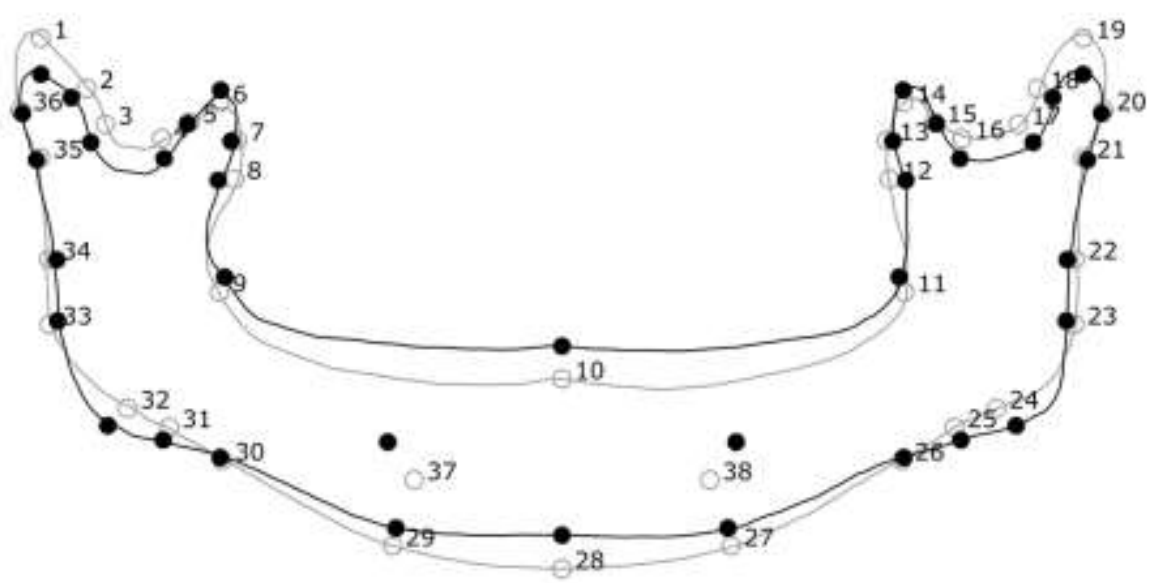




\section{Discussão}

As radiografias panorâmicas (RP) são registros diagnósticos que fornecem grande quantidade de informações. Quando associada à Morfometria geométrica (MG) permite identificar alterações da forma e tamanho das estruturas ósseas e mostrar a localização e extensão da deformação espacial (Fornel \& Cordeiro-Estrela, 2012; Gupta, 2017). Neste estudo, o uso da morfometria Geométrica permitiu identificar em RP de adultos jovens com terceiros molares inferiores erupcionados ou impactados, diferenças significativas na forma da mandíbula, mas não houve diferença com relação ao tamanho.

Estudos, utilizando a morfometria tradicional identificaram diferenças com relação ao tamanho da mandíbula, indicando que o comprimento total está diretamente relacionado a quantidade de crescimento condilar, e este comprimento influencia no espaço retromolar disponível (Björk et al., 1956). A deficiência no crescimento e redução do comprimento total da mandíbula são causas potenciais de impactação do terceiro molar inferior, assim como, a alta inclinação mesial da coroa do terceiro molar inferior com o ramo ascendente e rotação para baixo da mandíbula (Capelli, 1991; Lu \& Fan, 2019; Ray et al., 2018). Vale ressaltar que os achados diferenças podem estar associadas ao uso de diferentes métodos para a obtenção do tamanho.

$\mathrm{Na}$ literatura científica estudos que avaliaram o tamanho mandibular, geralmente utilizaram a morfometria tradicional, isto é, através de paquímetros de precisão e réguas obtêm medidas lineares (Fornel \& Cordeiro-Estrela, 2012). Este trabalho diferencia dos demais, visto que, a morfometria geométrica tem a capacidade de avaliar o tamanho generalizado a partir do tamanho do centróide, bem como avaliar as alterações do formato das estruturas, o que a torna capaz de avaliar as configurações geométricas, tornando o estudo mais robusto e com mais precisão nas mensurações. O tamanho do centroide é calculado a partir da raiz quadrada da soma das distâncias ao quadrado entre cada marco anatômico e o centróide ou centro de gravidade da forma (Bookstein, 1992). Com esta medida de tamanho é possível garantir a separação entre forma e tamanho com propriedades estatísticas desejáveis (Fornel \& Cordeiro-Estrela, 2012).

$\mathrm{Na}$ análise da forma da mandíbula as diferenças são percebidas nas bordas dessa estrutura, na região mentual e no côndilo. No que se refere as bordas do corpo da mandíbula, percebe-se que nas radiografias de usuários com dentes não impactados há uma contração da borda superior (11 e 9) e expansão na borda inferior (pontos anatômicos: 24,25,26,30,31,32) do corpo da mandibula, enquanto nos impactados foi o inverso. Logo, essas diferenças morfometricas podem ser justificadas pelo estudo de (Bjo"rk \& Skieller, 1972) que utilizou radiografias cefalometricas para avaliar a variação individual na direção e intensidade do crescimento observando que o padrão de rotação do crescimento mandibular é geralmente curvo para cima e para frente. $\mathrm{O}$ grau de rotação está associado com a reabsorção na borda inferior próximo ao ângulo da mandíbula e aposição abaixo da sínfise mentoniana. Segundo os autores a reabsorção na borda inferior do corpo da mandibula ocorre para fornecer o espaço para erupção dos dentes molares inferiores.

Ainda foi possível identificar a existência de um alongamento do côndilo $(1,19)$ para cima e expansão da região do mento para baixo (pontos anatômicos 27, 28, 29) em paciente com dentes impactados. De acordo com estudo conduzido por (Schudy, 1965) o crescimento nos côndilos mandibulares produz um componente para a forma da região do mento, isto é, o vetor final de crescimento do queixo é uma resultante da luta entre o crescimento condilar e o crescimento vertical dos molares. O crescimento dos côndilos estar tentando levar o queixo para a frente e o crescimento vertical combinado na área do molar está tentando levar o queixo para baixo. Quando o crescimento no côndilo é igual ao crescimento dos elementos verticais, o resultado geralmente é crescimento da mandíbula para baixo e para frente.

A direção do crescimento condilar está associada com processos de remodelação na borda inferior do corpo da mandíbula que recebe estímulos para reabsorver ou fazer a aposição do osso. Quanto maior a reabsorção, maior será o crescimento condilar na direção sagital (Björk et al., 1956). A direção do crescimento condilar estar intimamente relacionada com a direção do deslocamento (transposição) e desvios verticais da mandíbula. Em indivíduos com ângulos baixos, o 
crescimento mandibular é caracterizado pelo crescimento ântero-superior do côndilo, absorção da gônio e deslocamento anterior da mandíbula. Em contraste, indivíduos com ângulos elevados apresentam crescimento póstero-superior do côndilo, aposição do gônio e deslocamento ínfero-posterior da mandíbula (Mizoguchi et al., 2013).

Por ser um estudo de caráter exploratório os resultados funcionam como um ponto de partida. Essas informações podem auxiliar na compressão da etiologia da impactação de terceiros molares inferiores. Como limitação o fato de não ter sido considerado a etnia dos indivíduos, não houve analise do tamanho dos dentes em relação ao tamanho da mandíbula e não houve paridade entre o número de radiografias entre os grupos com terceiros molares impactados ou não. Vale destacar que estas limitações não interferiram nos resultados obtidos. Apesar das limitações as investigações demonstraram que é vantajoso usar a MG para localizar as alterações na mandíbula

\section{Conclusão}

Os resultados obtidos permitem concluir que o uso da morfometria geométrica para análise de imagens da mandíbula em radiografias panorâmicas de adultos jovens com e sem a presença de terceiros molares impactados não identificou diferença significativa para o tamanho da mandíbula. Entretanto, foram identificadas diferenças significativas na forma óssea mandibular entre indivíduos com e sem terceiros molares impactados. As alterações observadas foram situadas na região do mento, côndilo e borda do corpo da mandíbula. Nas radiografias de pessoas com terceiros molares impactados houve encurtamento da região mentual e do côndilo da mandíbula. Como esse estudo não levou em consideração o tamanho dos dentes em relação a mandíbula, pode ser um ponto de partida para trabalhos futuros.

\section{Referências}

Adams, D. C., Rohlf, F. J., \& Slice, D. E. (2004). Geometric morphometrics: Ten years of progress following the 'revolution'. Italian Journal of Zoology, 71(1), 5-16. https://doi.org/10.1080/11250000409356545

Adeyemo, W. L., James, O., Oladega, A. A., Adamson, O. O., Adekunle, A. A., Olorunsola, K. D., Busch, T., \& Butali, A. (2021). Correlation Between Height and Impacted Third Molars and Genetics Role in Third Molar Impaction. Journal of Maxillofacial and Oral Surgery, 20(1), 149-153. https://doi.org/10.1007/s12663-020-01336-9

Ali, D. W. M. (2015). Body and local factors affecting eruption of third molar tooth. 12(1), 10.

Ara, S. A., \& Ayesha, H. (2016). Correlation between developmental stages of mandibular third molar and retromolar space. International Journal of Maxillofacial Imaging, 6.

Björk, A., \& Skieller, V. (1972). Facial development and tooth eruption. American Journal of Orthodontics, 62(4), 339-383. https://doi.org/10.1016/S00029416(72)90277-1

Björk, A., Jensen, E., \& Palling, M. (1956). Mandibular growth and third molar impaction. Acta Odontologica Scandinavica, 14(3), 231-272. https://doi.org/10.3109/00016355609019762

Bookstein, F. L. (1986). Size and Shape Spaces for Landmark Data in Two Dimensions. Statistical Science, 1(2). https://doi.org/10.1214/ss/1177013696

Bookstein, F. L. (1992). Morphometric Tools for Landmark Data: Geometry and Biology Cambridge University Press. https://doi.org/10.1017/CBO9780511573064

Buck, T. J., \& Vidarsdottir, U. S. (2004). A Proposed Method for the Identification of Race in Sub-Adult Skeletons: A Geometric Morphometric Analysis of Mandibular Morphology. Journal of Forensic Sciences, 49(6), 1-6. https://doi.org/10.1520/JFS2004074

Capelli, J. (1991). Mandibular growth and third molar impaction in extraction cases. The Angle Orthodontist, 61(3), 223-229. https://doi.org/10.1043/00033219(1991).

de Menezes, M., \& Sforza, C. (2010). Three-dimensional face morphometry. 3.

Ferreira, W. de B., Nunes, L. A., Pithon, M. M., Maia, L. C., \& Casotti, C. A. (2020). Craniofacial geometric morphometrics in the identification of patients with sickle cell anemia and sickle cell trait. Hematology, Transfusion and Cell Therapy, 42(4), 341-347. https://doi.org/10.1016/j.htct.2019.10.003

Fornel, R., \& Cordeiro-Estrela, P. (2012). Morfometria geométrica e a quantificação da forma dos organismos. https://doi.org/10.13140/2.1.1793.1844

Gamba, T. de O., Alves, M. C., \& Haiter-Neto, F. (2016). Mandibular sexual dimorphism analysis in CBCT scans. Journal of Forensic and Legal Medicine, 38, 106-110. https://doi.org/10.1016/j.jflm.2015.11.024 
Research, Society and Development, v. 10, n. 5, e2910514509, 2021

(CC BY 4.0) | ISSN 2525-3409 | DOI: http://dx.doi.org/10.33448/rsd-v10i5.14509

Gupta, B. (2017). Radiological assessment of impacted mandibular third molar teeth. 2(9), 4.

Klingenberg, C. P. (2013). Visualizations in geometric morphometrics: How to read and how to make graphs showing shape changes. Hystrix, the Italian Journal of Mammalogy, 24(1). https://doi.org/10.4404/hystrix-24.1-7691

Klingenberg, C. P., \& Monteiro, L. R. (2005). Distances and Directions in Multidimensional Shape Spaces: Implications for Morphometric Applications. Systematic Biology, 54(4), 678-688. https://doi.org/10.1080/10635150590947258

Klingenberg, P. C. (2019). Morphoj. Java vendor: oracle Corporation. https://tpsutil.software.informer.com/Download-gr\%C3\%A1tis/

Lisboa, A. H., Gomes, G., Hasselman Junior, E. A., \& Pilatti, G. L. (2012). Prevalência de Inclinações e Profundidade de Terceiros Molares Inferiores, segundo as Classificações De Winter e De Pell \& Gregory. Pesquisa Brasileira em Odontopediatria e Clínica Integrada, 12(4), 511-515. https://doi.org/10.4034/PBOCI.2012.124.10

Lopes, L. S., Cardoso, L. S., Morais, M. N. da S., Ferreira, M. U., Paula, L. G. F. de, \& Mariano-Júnior, W. J. (2020). Prevalência dos tipos de impacção de terceiros molares na clínica odontológica de ensino do centro universitário de anápolis - Unievangélica. Scientific Investigation in Dentistry, 24(1), 13-22. https://doi.org/10.37951/2317-2835.2019v24i1.p13-22

Lu, D., \& Fan, Y. (2019). Factors Affecting Impaction of Wisdom Teeth and Their Mechanisms. In D. Lu (Org.), Atlas of Wisdom Teeth Surgery (p. 19-23). Springer Singapore. https://doi.org/10.1007/978-981-10-8785-1_2

Mitteroecker, P., \& Gunz, P. (2009). Advances in Geometric Morphometrics. Evolutionary Biology, 36(2), 235-247. https://doi.org/10.1007/s11692-0099055-x

Mizoguchi, I., Toriya, N., \& Nakao, Y. (2013). Growth of the mandible and biological characteristics of the mandibular condylar cartilage. Japanese Dental Science Review, 49(4), 139-150. https://doi.org/10.1016/j.jdsr.2013.07.004

Nunes, L. A., Jesus, A. S., Casotti, C. A., \& Araújo, E. D. de. (2018). Geometric morphometrics and face shape characteristics associated with chronic disease in the elderly. Bioscience Journal, 1035-1046. https://doi.org/10.14393/BJ-v34n2a2018-39620

Palmer, A. R. (1994). Fluctuating asymmetry analyses: A primer. In T. A. Markow (Org.), Developmental Instability: Its Origins and Evolutionary Implications (2, 335-364). Springer Netherlands. https://doi.org/10.1007/978-94-011-0830-0_26

Pinto, L. L. T., Carmo, T. B. do, Sales, A. S., Nunes, L. A., \& Casotti, C. A. (2020). Metabolic syndrome components and face shape variation in elderly. Revista Brasileira de Cineantropometria \& Desempenho Humano, 22, e74390. https://doi.org/10.1590/1980-0037.2020v22e74390

Ray, S., Datana, S., Jain, A., Sharma, M., \& Mp, P. K. (2018). Correlation of Impaction of Mandibular Third Molars with Sagittal Dimension of Face. International Journal of Contemporary Medicine, Surgery and Radiology, 3(4). https://doi.org/10.21276/ijcmsr.2018.3.4.30

Rohlf, F. (2015). The tps series of software. Hystrix, the Italian Journal of Mammalogy, 26(1). https://doi.org/10.4404/hystrix-26.1-11264

Rohlf, FJ. (2017a). Relative Warps: Ecology e Evolution and Anthropoly (1.69) [Computer software]. https://tpsrelw.software.informer.com/1.5/

Rohlf, FJ. (2017b). tpsDig 2: Ecology e Evolution and Anthropoly (2.31). https://tpsdig2.software.informer.com/1.1/

Rohlf, FJ. (2019). tps Utility Program: Ecology e Evolution and Anthropoly (1.69) [Computer software]. https://tpsutil.software.informer.com/Downloadgr\%C3\%A1tis/

Schudy, F. F. (1965). The rotation of the mandible resulting from growth: Its implications in orthodontic treatment. The Angle Orthodontist, 35, 36-50. https://doi.org/10.1043/0003-3219(1965).

Slice, D. E. (2007). Geometric Morphometrics. Annual Review of Anthropology, 36(1), 261-281. https://doi.org/10.1146/annurev.anthro.34.081804.120613

Toro-Ibacache, V., Ugarte, F., Morales, C., Eyquem, A., Aguilera, J., \& Astudillo, W. (2019). Dental malocclusions are not just about small and weak bones: Assessing the morphology of the mandible with cross-section analysis and geometric morphometrics. Clinical Oral Investigations, 23(9), 3479-3490. https://doi.org/10.1007/s00784-018-2766-6 